\author{
M. Szkodo ${ }^{1}$, A. Stanisławska ${ }^{1}$, P. Śliwiński ${ }^{2}$ \\ Gdansk University of Technology, Faculty of Mechanical Engineering \\ ${ }^{1}$ Department of Materials and Welding Engineering, \\ ${ }^{2}$ Department of Mechanic and Mechatronic, \\ 11/12 Narutowicza Street, 80-233 Gdansk, Poland \\ mszkodo@pg.gda.pl,alistanislawska@gmail.com, pawsliwi@pg.gda.pl
}

\title{
ON THE DURABILITY OF THE HYDRAULIC SATELLITE MOTOR WORKING MECHANISM IN OVERLOAD CONDITION
}

\begin{abstract}
The paper presents the newest construction of the hydraulic satellite pump/motor. In this study, the fracture of the hydraulic satellite motor working mechanism is investigated. Factors influencing the durability of satellite working mechanism have been described. The durability of the hydraulic satellite motor working mechanism at a load, corresponding to a pressure of $15 \mathrm{MPa}$ supplied with refined rapeseed oil is very low. Analyses of construction and laboratory tests showed that the satellites teeth wear out the fastest. Results showed that bending fatigue and surface contact fatigue of the satellites are the main cause of the hydraulic satellite motor working mechanism failures.
\end{abstract}

Keywords: satellite motor, working mechanism, gears, rapeseed oil

\section{INTRODUCTION}

A gear pump is a mechanical pump that moves liquids with the use of two rotating gears. Liquid flows under pressure from the pump intake to the discharge in the space formed by the gear teeth. The liquid also serves to lubricate the gears. The small clearances between the walls of the pump chamber and gear teeth create a tight seal, thereby preventing liquid from flowing back through the intake. Unlike other types of pumps, gear pumps do not need to be primed and can be run dry for short periods without damaging the pump. They are typically used to pump water, oil and other liquids.

There are two main types of gear pumps, internal and external. The internal gear pump, also known as a gerotor, has two gears. A smaller internal gear fits inside a larger one and both rotate in the same direction. The smaller gear always has one less tooth than the larger one and is mounted off-center in relation to the shaft of the larger gear. This allows the internal gear to rotate freely inside the external gear, while at the same time providing the space needed to pump the liquid from the intake to the discharge of the gear pump. Power is applied to the shaft of the internal gear, which then drives the external gear.

External gear pumps have two identical gears that rotate in opposite directions. Liquid is transported in the space created between the teeth of the gear and the sides of the pump 
chamber. Power is applied to the shaft of the driving gear, which in turn drives the other gear. Spur gears are usually used in external gear pumps, although helical and herringbone gears are sometimes used when excessive pump noise is a concern.

In the Division of Hydraulics and Pneumatics of Gdansk University of Technology has been carried out development research on hydraulic satellite motor/pump [1-6]. The newest construction of the motor/pump, developed by the P. Sliwinski, is a combination of internal and external gear pump (see Fig. 1).
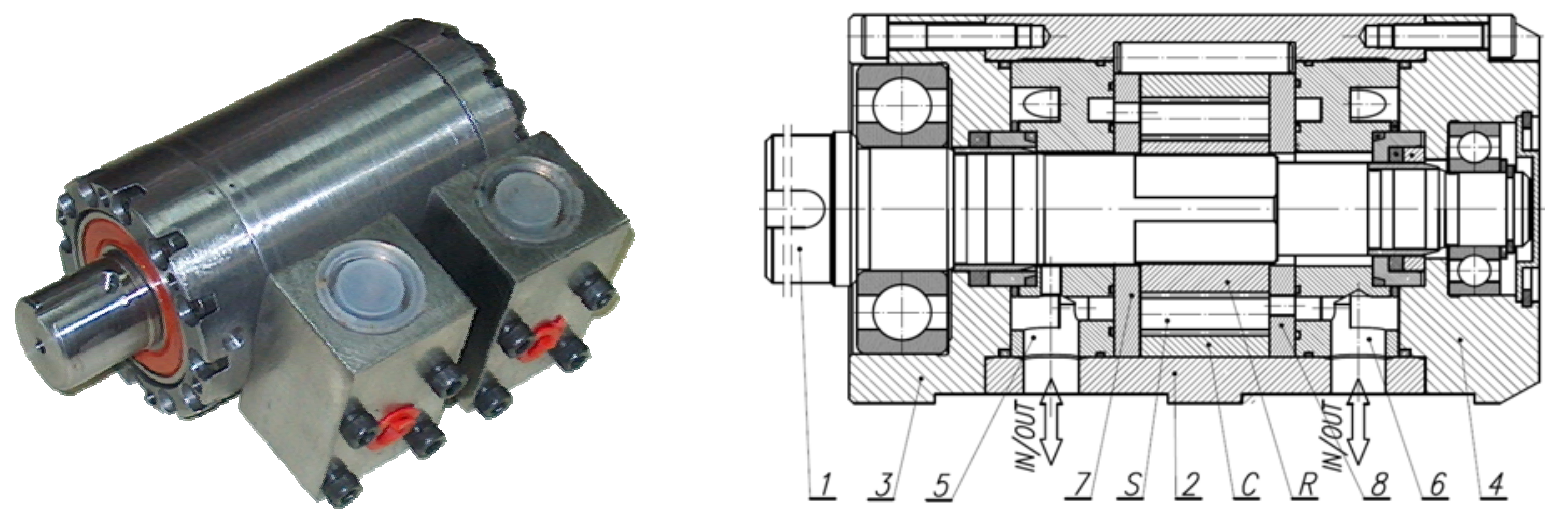

Fig. 1. General view and cross section of the satellite motor/pump SM-06: C - curvature, $S$ - satellite, $R-$ rotor, 1 - shaft, 2 - body, 3 - front body, 4 - rear body, 5 and 6 - in/out manifolds, 7 and 8 - compensation plates. Own study based on [21]

The working mechanism of the pump is a gear mechanism (Fig. 2) and consists of: rotor R (4 humps), curvature $\mathrm{C}$ (6 humps) and gear wheels $\mathrm{S}$ (satellites). The number of satellites is the sum of humps of rotor and humps of curvature (10 satellites in this case). The teeth profile of the curvature, rotor and satellites are involute only in the area of cooperation teeth [1]. Outside the area of cooperation, in the foot of the tooth, the profile is arc, which eliminated the undercut of the tooth. Thus, the tooth is strengthened at the base. Implementation of such gearing is only possible by the electrodischarge machining.

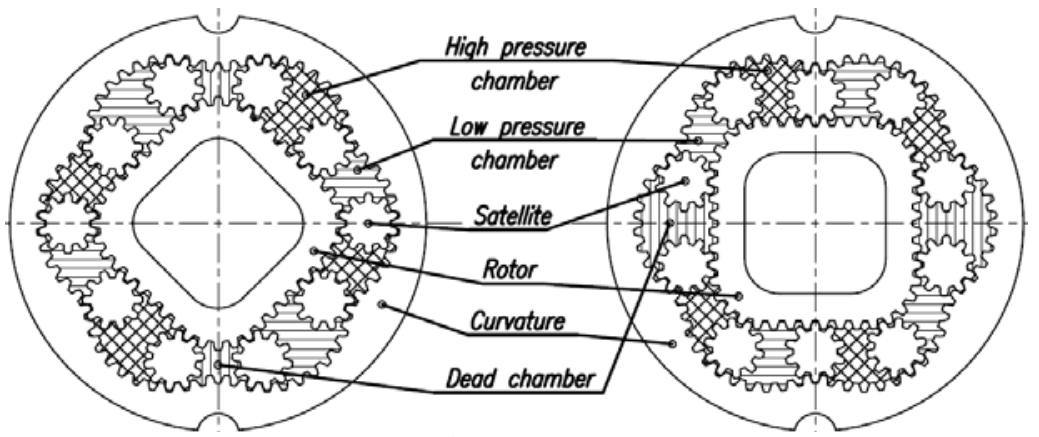

Fig. 2. Working mechanism of satellite motor/pump (on the left) and place of occurrence of leakages (on the right). Own study based on [22]

The principle of operation of the working mechanism (satellite mechanism) is as follows. When the rotor rotates, then the space between two satellites is changing its delivery. In this way, when delivery increases then it is suction process and when delivery decreases then it is press process. On one turn of the shaft there are 24 working cycles. Spaces in satellite' mechanism are closed by two commutation plates (Fig. 1 (item 7 and 8) and Fig. 2). The commutation plates play the role of the compensation plates simultaneously. In this way the satellite motor includes axial clearances compensation. 
The satellite motors are designed for small mechanization in the mining industry, mainly for driving hand tools. Therefore, against the background of other hydraulic motors, the satellite motors are characterized by the smallest overall dimensions and weight. Power to weight ratio of these motors is more than 4.

In mines, hydraulic motors must be operated with non-flammable liquids, such as emulsion HFA-E and water. These engines are also used in other industries. Therefore, for the first time, have been conducting research of satellite motor/pump supplied with refined rapeseed oil. Such oil is widely available and has a satisfactory lubricating properties. The worst lubricating properties has water [7]. The aim of this work is the analysis of damage of the satellite motors/pump caused by overload.

\section{Failure mechanisms of a gear pumps}

Surface contact fatigue is the most common cause of gear failures. Three forms of surface contact fatigue damage can be identified, depending on the stress distribution at and near the surface. The characteristics of each type of failure can be summarized as follows [8]: (a) Rolling contact fatigue occurs along the pitch-line of gear teeth and leads to the formation of microscopic pits. (b) Sliding-rolling contact fatigue occurs away from the pitch-line, but predominantly in the dedenda of gear teeth, where negative sliding conditions prevail. This form of damage leads to the formation of surface pits which may act as initiation sites for other modes of failure. (c) Spalling refers to the formation of large, deep pits on contacting surfaces, and is either a continuation of rolling or rolling sliding contact fatigue damage, or may be due to cracking at the case-core interface.

The second mechanism of failure of gear pump is bending fatigue. The maximum tensile stresses occur at the root radius on the active (i.e. loaded) flank of the gear tooth, while the maximum compressive stresses occur at the root radius on the passive flank [9]. A zero-stress point therefore exists below the root circle at or near the tooth center-line [10]. Depending on the geometry of the gear tooth and the characteristics of loading, the stress concentration at the root radius where maximum tensile stresses are experienced may vary from 1.4 to 2.5 [11]. With the cyclic variation in loads characteristic of gear operation, these regions become preferential sites for fatigue crack initiation.

\section{Material requirements for steel gear}

To satisfy all the requirements, a material characterized by high toughness is advisable to resist to fatigue bending stress and impact stress, whereas high hardness and fatigue strength must be guaranteed to prevent respectively wear damage and sub-superficial cyclic loading. Such differences in the same material are achieved by the use of thermal and thermochemical surface treatments. For this reason, gears are often surface hardened by nitriding[12]. Nitriding is performed on quenched and tempered steel, and can be conducted at temperature lower than tempering itself, therefore not involving microstructural changes. Not implying substantial deformations, this treatment can be conducted on the component finished. A high effective case depth (the depth of nitrided layers) has to guarantee the achievement of the good resistance to contact fatigue. It derives from the Hertz theory about the contact between two elastic bodies. As can be seen from Hertz theory [13] the contact produce below the surface (along the contact axis) a stress field characterized by three main stresses (compressive) and the shear stress which reaches its maximum value at a certain distance below the surface. This peak of the shear stress is assumed to be the main responsible for microcracks initiating in material which propagate in the material under cyclic loading 
leading to component failure. On the other hand Sekercioglu [14] reported that gears could be produced with low alloy steels which ought to be carburized or nitrided. He concluded that using a nitride alloyed steel, case hardening can be done and a very hard and thin case depth ought to be obtained. A thin hard case may be better than too thick one because when the thickness of the nitrided layer increases the depth of the zone interested by compressive residual stresses becomes greater. These must be balanced; close to the case-core interface, by residual tensile stresses [12]. In turn Genel and Demirkol [15] reported that the fatigue strength of carburized AISI 8620 steel, with a core hardness of $300 \mathrm{HV}$, increasing with increased hardened case depth up to the critical limit value of 0.12 . But they concluded that if the risk of easy crack initiation and growth is considered, an increase in the case depth exceeding the limiting value can not be recommended for machine parts which have been subjected to a carburizing treatment.

\section{Tested motor, working liquids and test parameters}

Laboratory durability tests of satellite motor SM-0,6/20 were carried out. This engine is characterized by the following parameters:

tooth module $-0,6 \mathrm{~mm}$, height of the operating mechanism $-20 \mathrm{~mm}$, theoretical displacement $-16,7 \mathrm{~cm}^{3} / \mathrm{rev}$.

Prior to designing the engine assumed maximum working pressure of the engine $25 \mathrm{MPa}$. However, calculations have shown that for pressure 20 and $25 \mathrm{MPa}$ the condition is satisfied only for tooth bending strength. That is the working pressure of $20 \mathrm{MPa}$ is too large and so the load of $50 \mathrm{Nm}$ is the motor overload. It was decided, however, to check what will be the durability of the operating mechanism at the pressure $20 \mathrm{MPa}$. For comparison, it was decided to check the durability of the engine at a lower load, corresponding to a pressure of $15 \mathrm{MPa}$. The elements of SM-0.6/20 engines which were running in different mode were studied. Modes were marked as: "A", "B" and "C" and their characteristic are shown below in Tab. 1.

Table. 1. Various engine operating modes

\begin{tabular}{llll}
\hline Mode & Working fluid & Speed & Decrease pressure \\
\hline A & $1 \%$ emulsion HFA- & $1500 \mathrm{rpm}$ & $20 \mathrm{MPa}$ \\
& E*) $\left.^{*}\right)$ & & \\
B & refined rapeseed oil & $1500 \mathrm{rpm}$ & $20 \mathrm{MPa}$ \\
C & refined rapeseed oil & $1500 \mathrm{rpm}$ & $15 \mathrm{MPa}$
\end{tabular}

*) $1 \%$ concentrate ISOSYNTH VX110-BF in tap water

This paper presents results for engine's elements which were running in $\mathrm{C}$ mode.

\section{Influence of construction factors on the teeth wear}

During the phase of operating mechanism design numerical calculations of stresses in the teeth was carried out. Assumed the most unfavourable position of the satellite relative to the rotor. This is an area of five teeth on the rotor hump (Fig. 3). In this area the pitch diameter PD-R of the rotor is smallest. Due to the small number of teeth (ten) on the satellite receives a small tooth contact ratio. This affects the unfavourable distribution of interstate force. 


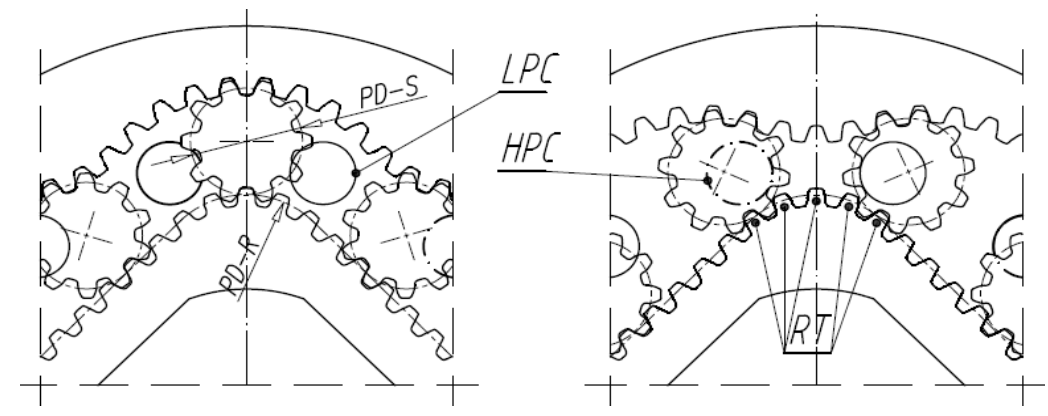

Fig. 3. The characteristic position of the rotor and satellites: RT - rotor teeth most loaded, HPC - supply channel (high pressure), LPC - outflow channel (low pressure), PD-R - pitch diameter of the rotor hump, PD-S - pitch diameter of the satellite

Satellite is pressed against the force of the rotor and the piston proportional to the pressure difference $\Delta \mathrm{p}$. At $\Delta \mathrm{p}=25 \mathrm{MPa}$ the nominal force acting on the tooth is $1500 \mathrm{~N}$. Numerical calculations were performed for a mechanism made from steel Nimax [16], assuming that the mechanism is stationary. The calculation results showed that the stresses at the base of the tooth are $500 \mathrm{MPa}$ (Fig. 4). The contact stresses at the contact point of teeth reach a value of $2000 \mathrm{MPa}$. Furthermore, after the load of motor shaft, deforms both the shaft and the planet (Fig. 4).
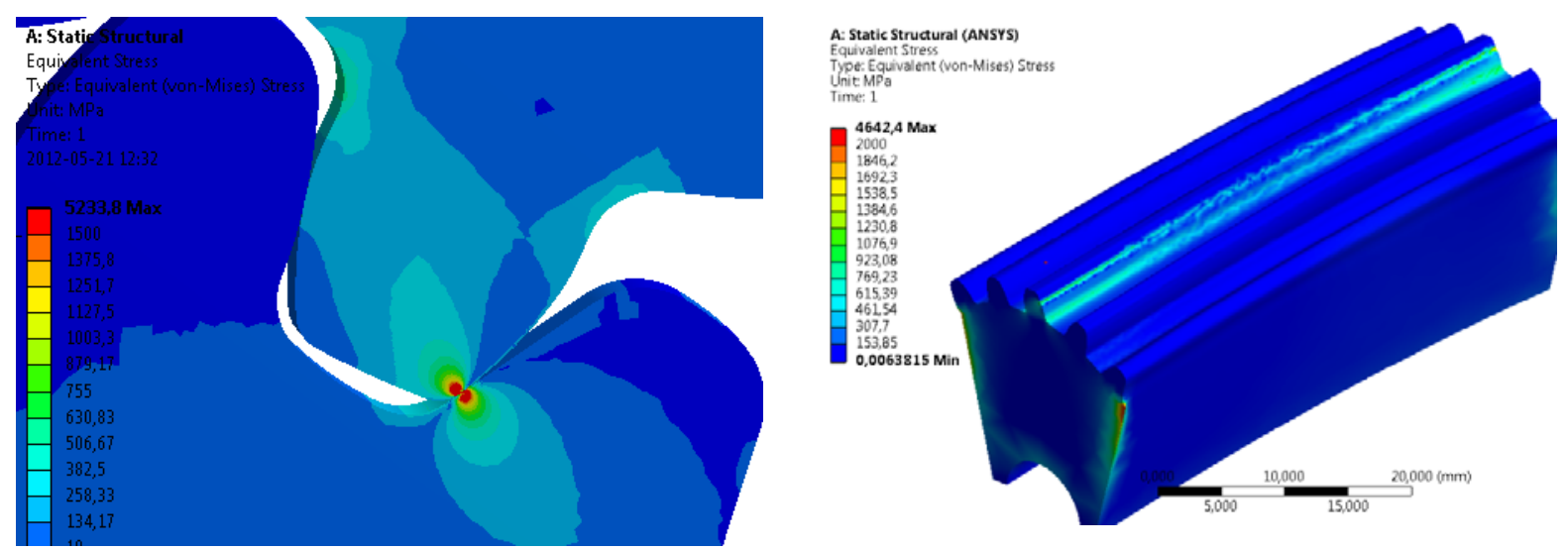

Fig. 4. Stress distribution at the contact point of the rotor with satellite (on the left) and stress distribution along the length of the tooth (on the right)

During engine operation, the teeth of operating mechanism are subject to variable loads. It was calculated that:

allowable stress $\sigma_{\mathrm{Fp}}$ for fatigue break the tooth are $520 \mathrm{MPa}$;

allowable stress $\sigma_{\mathrm{Hp}}$ for fatigue tooth surface amounts to $710 \mathrm{MPa}$.

So the condition for the fatigue strength of the surface has not been met. Furthermore, it should be noted that the satellites are moving freely in the tip clearances. Thus, as a result of the pressure difference, in the teeth cooperation area occur slippage. This is an additional reason for accelerating the process of tooth wear. In the operating mechanism, on one shaft revolution, the number of loads of each tooth is:

4 - for curvature (equals the number of the humps on the rotor);

6 - for rotor (equals the number of the humps on the curvature);

5 - for satellite (equals the average of the amount of humps of the rotor and the curvature).

From this the conclusion that the rotor teeth will wear the fastest. With the engine running at $1500 \mathrm{rev} / \mathrm{min}$ for one hour the number of load cycles of each tooth of the rotor is 540 
thousands. In addition, on the durability of the operating mechanism has an impact rotational speed. When rotor speed is $1500 \mathrm{rev} / \mathrm{min}$, then satellites move with flat, with variable speed, in the range of $2849 \div 3501 \mathrm{rev} / \mathrm{min}$. This causes additional forces of inertia loading teeth.

\section{Material used to build the mechanism and research methodology}

For study used 10 satellites with a face width of $20 \mathrm{~mm}$ and a diameter (addendum circle) of $12 \mathrm{~mm}$, and the rotor hump. Chemical composition of steel used to build the mechanism and the heat treatment and thermo chemical treatment parameters are presented in Tab. 2.

Table 2. Chemical composition (wt. \%), heat treatment and thermo chemical parameters of processed steel

\begin{tabular}{lllllllll}
\hline $\mathrm{C}$ & $\mathrm{Mn}$ & $\mathrm{Cr}$ & $\mathrm{Ni}$ & $\mathrm{S} \max$ & $\mathrm{P} \max$ & $\begin{array}{l}\text { Hardening } \\
{\left[{ }^{\circ} \mathrm{C}\right]}\end{array}$ & $\begin{array}{l}\text { Tempering } \\
{\left[{ }^{\circ} \mathrm{C}\right]}\end{array}$ & $\begin{array}{l}\text { Nitriding } \\
{\left[{ }^{\circ} \mathrm{C}\right]}\end{array}$ \\
\hline 0.4 & 2.5 & 2.95 & 0.95 & 0.030 & 0.030 & 900 & 600 & 500
\end{tabular}

Microstructure of rotor, satellites and curvature is presented in Fig. 5. After the quenching and tempering the microstructure of steel consisted of high tempered martensite and its hardness was $380 \mathrm{HV} 30$. After nitriding case microstructure consisted of a mixture of high tempered martensite and chromium and iron nitrides as presented in Fig. 5. The average case hardness of nitrided steel was $1100 \mathrm{HV} 0.1$ (ranged from 1080HV to 1180HV). The depth of the hardened case was $0.4 \mathrm{~mm}$.

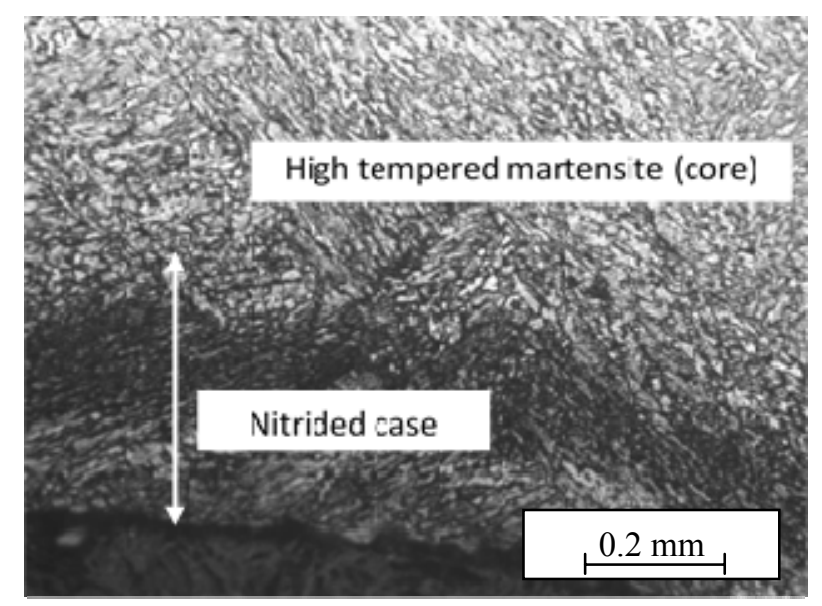

Fig. 5. Microstructure of steel used to build the mechanism. Visible high tempered martensite in core and the mixture of high tempered martensite and chromium and iron nitrides in case. LM

Microscopic examinations of etching and not etching specimens were performed using a light microscope Leica MEF4 (LM) and scanning electron microscope PHILIPS FEI XL 30 (SEM). Before microscopic examination metallographic sections were prepared by grinding on abrasive papers and then mechanical polishing. Polished samples were observed using LM and then etching due to microstructural examination.

The microhardness study of nitrided surface layers (case) and steel core were made for all the samples. Microhardness tests performed using Vickers method. The study was performed for load $0.05,0.1$ and $0.2 \mathrm{kG}$ to verify which load cause obtain the highest values of case microhardness . The hardness examination of the core of samples was performed using a Vickers hardness tester, for a load of $30 \mathrm{kG}$. 


\section{FAILURE ANALYSIS AND DISCUSSION}

The experimental research shows that the satellite mechanism is characterized by a very low durability under overload condition. The following factors on the durability of the motor operating mechanism have an impact:

a) the construction of the operating mechanism;

b) the type of steel used for the elements of the mechanism;

c) the kind and quality of the thermo-chemical treatment;

d) the working fluid [17].

In hydraulics, it is assumed that the durability of the hydraulic motor should be about 10 thousand hours. Assuming that the engine is running at a speed of $1500 \mathrm{rev} / \mathrm{min}$, the durability of the teeth should be at least 900 million cycles. Thus, the stability under overload conditions, at the pressure drop in the engine $15 \mathrm{MPa}$, is at least 36 times less than the nominal. Therefore, should be lowered rated working pressure of the engine, reduce its speed and should be chosen of a higher strength steel with a suitably chosen heat and thermo chemical treatment.

After working in refined rapeseed oil for 46 hours, at a drop pressure of $15 \mathrm{MPa}$ and rotational speed of $1500 \mathrm{rpm}$ the satellites and rotor teeth were destroyed. Time after occurred the destruction of mechanism was 46 hours - for mode C, which corresponds to 24,8 million load cycles of the rotor teeth. In structures subjected to heavy cyclic loading, fatigue damage of material during cyclic plasticity-elasticity is one of the most frequent failure mechanisms. Fig. 6 shows an example of teeth wear on the rotor hump and satellites. There is visible that cracked satellites teeth were deflected and teeth bending fatigue led to failure of a number of adjacent satellites teeth (Fig. 6b).
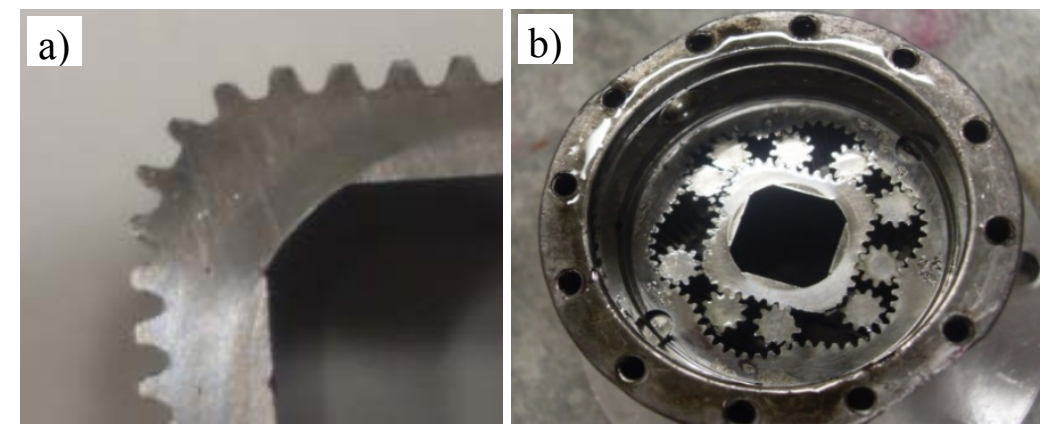

Fig. 6. Teeth wear on the rotor hump - Fig. 6a), and destroyed elements of the working mechanism - Fig. 6b)

Microscopic examination revealed that all teeth fractures resulted from fatigue damage. Broken teeth showed typical mixed brittle and ductile fatigue fracture (Fig. 7). The satellites teeth were broken - typically at the place where was the biggest bending i.e. near the bottom land as presented in Fig. 8a. Fatigue cracks originated at the active flank of the satellite teeth (Fig. 8b). Sometimes a crack that first developed as a single branched off and further developed as a parallel cracks as shown in the Fig. 9. 


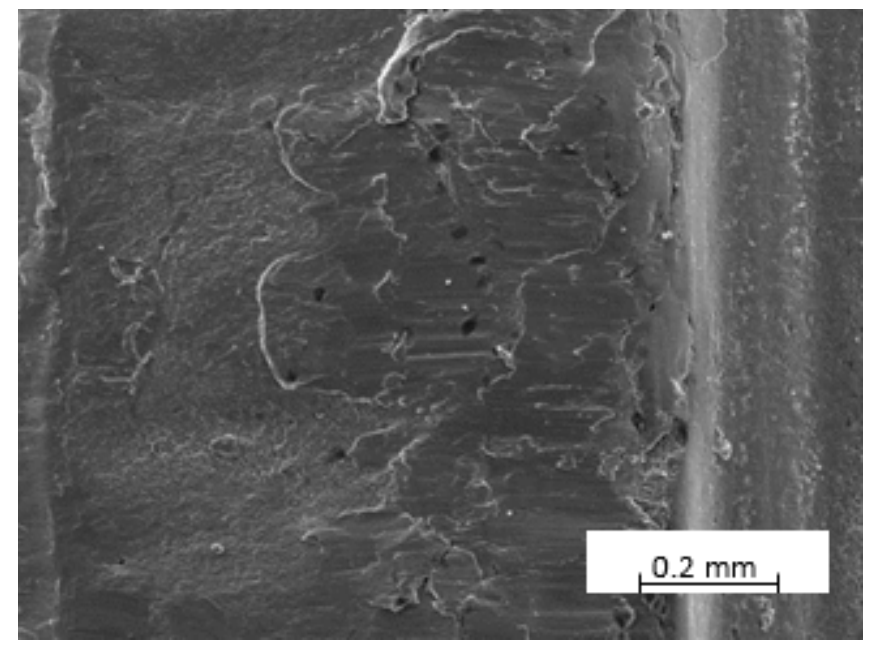

Fig. 7. Visible mixed brittle and ductile fatigue fracture of broken tooth of the satellite. SEM

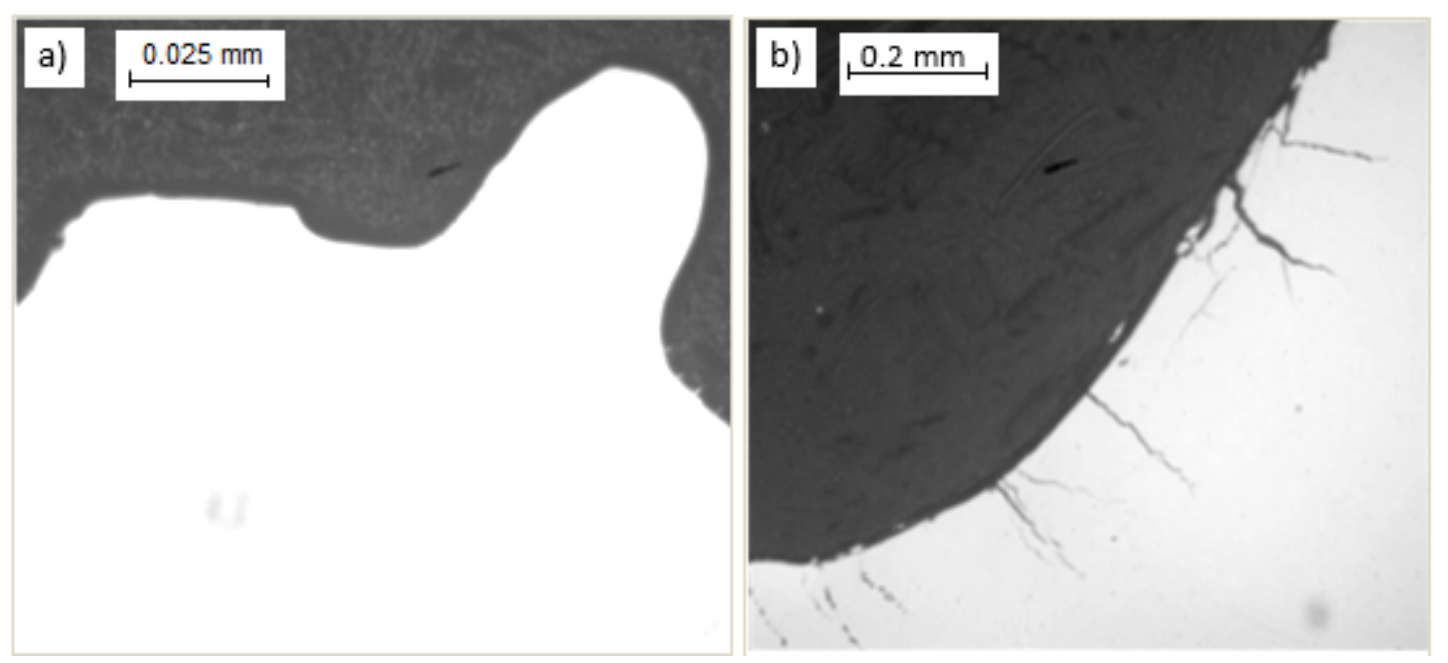

Fig. 8. Visible broken satellite tooth. LM - Fig. 8a and cracks developed near the root circle perpendicular to the surface tooth, LM - Fig. 8b

Several causes of tooth bending fatigue failure have been identified [18]. These include poor design of the gear sets, incorrect assembly or misalignment of the gears, or the use of incorrect materials and heat treatments. In this case, it seems that the cause of tooth bending fatigue failure was overload. Metallographic investigations reveled also surface contact fatigue of the satellites and rotor teeth.

Fig. 10 presents the damaged tip corner of satellite tooth. This site of the tooth is called geometric stress concentration. Due to repetitive stress concentration at the tip corner of the tooth micropitting occurred leading to slice off chunks of the material.

Fig. 11 presents split off on the active flank of the satellite tooth. This macropit is situated at the dedenda and it is an effect of sliding-rolling fatigue. Place of location of the defect can attest to the fact that it is the result of a negative sliding i.e. direction of rolling velocity was opposite sliding velocity. The effect of the latter is that the surface material is rolled in one direction, and sliding in another, therefore resulting in higher stresses than those encountered in positive sliding [19]. In the addendum, the direction of rolling and sliding is the same, and positive sliding conditions therefore prevail. In the dedendum, however, the direction of rolling is opposite to that of sliding, and negative sliding conditions exist. Contact fatigue is therefore more likely to initiate in the dedendum, and pitting in this region is usually very 
severe, and often acts as a precursor to tooth bending fatigue [9]. Negative sliding is also significant because it promotes Hertzian fatigue by allowing oil to enter surface cracks where it accelerates crack growth by the hydraulic-pressure-propagation mechanism [20]. It is possible that in the first stage of damage micropits initiated due to a rolling or sliding-rolling fatigue and the damage was continuing in the second stage as a spalling. Spalling is the cracking and flaking of particles out of a surface. Microscopic investigation revealed that spalling occurred as a continuation of pitting resulting from rolling or sliding-rolling contact fatigue as presented in Fig. 12. The cracks initiated by these mechanisms propagated into the material, and ultimately result in the loss of large pieces of metal from the contact surface (see Fig. 11b). Microscopic investigation revealed also another mechanism of spalling called "subcase fatigue" or "case crushing" [19]. Fatigue cracks were formed and propagated between the hardened case and core as presented in Fig. 13. Fatigue cracks initiated probably at the metallurgical notch formed between the hardened case and core [19]. The mechanism of crack initiation was the same as in the other modes of contact fatigue. This type of spalling is due to the disparity in the mechanical properties of the case and core. Increasing the hardness of the core through material selection or heat treatment can effectively reduce the incidence of this kind of spalling [8].

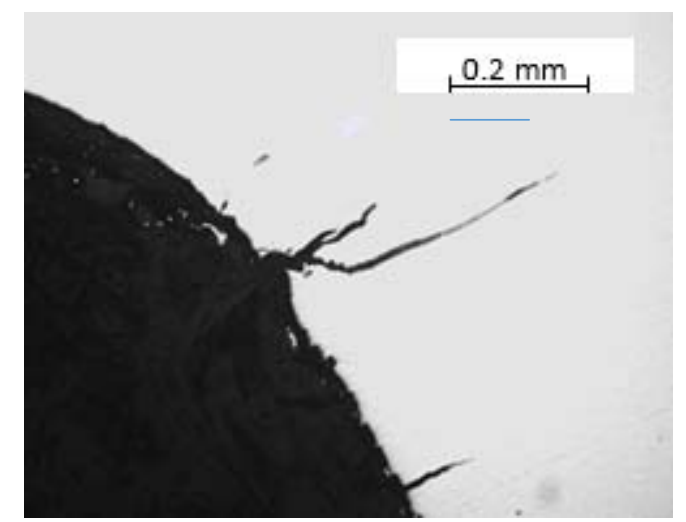

Fig. 9. Tooth of the rotor nearby the root circle. Visible crack developed perpendicular to the surface first as a single and next as a parallel cracks. LM

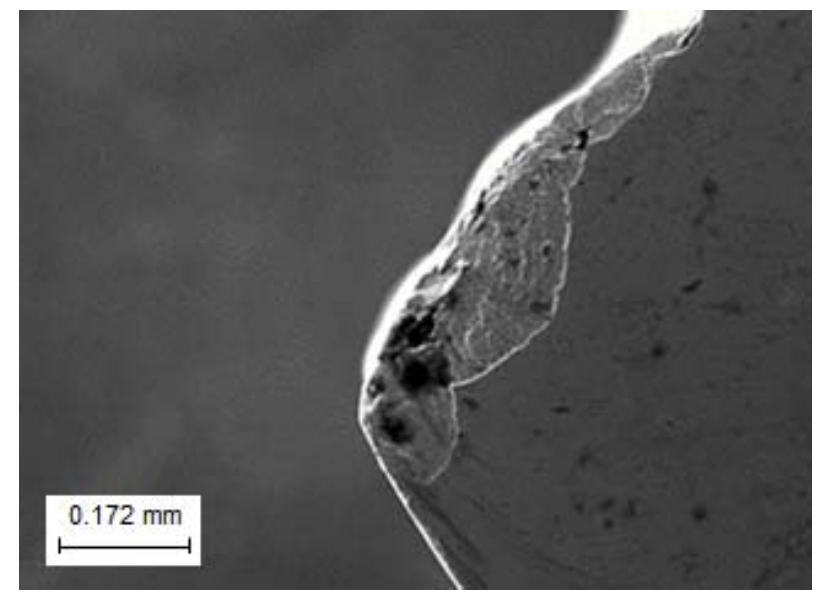

Fig. 10. The damaged tip corner of the satellite tooth. Visible chip of the material. SEM 


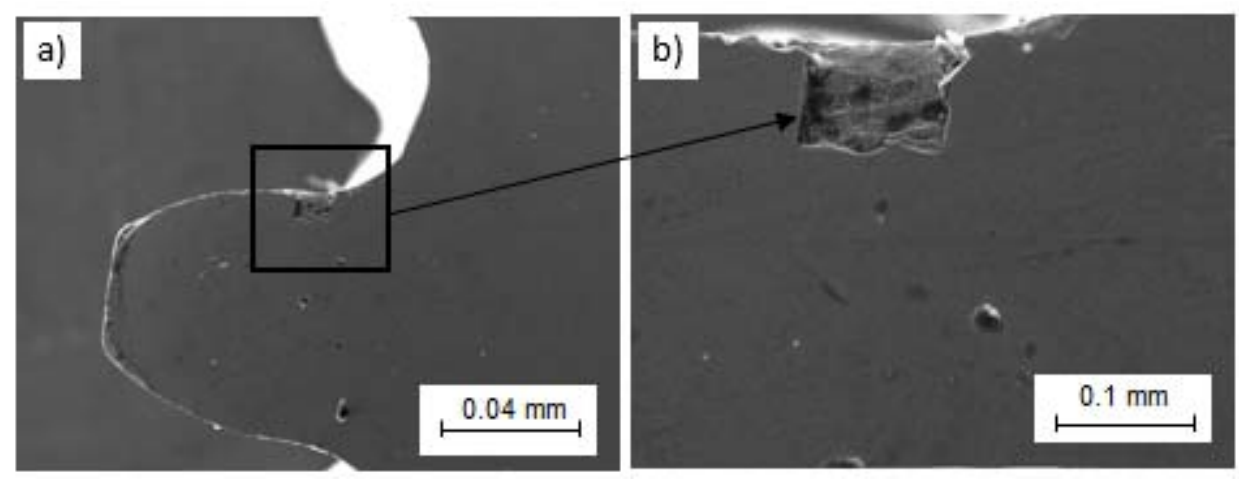

Fig. 11. Visible macropit on the active flank of the satellite tooth - Fig. 11 a), and the same portion of the area Fig. 11 b) SEM

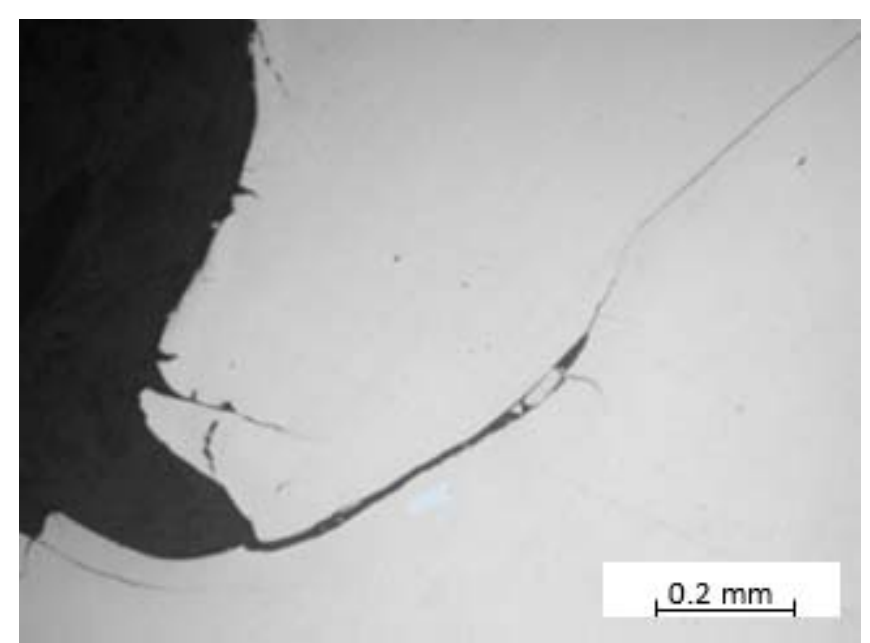

Fig. 12. Satellite. Visible crack initiated at the bottom of the micropit. LM

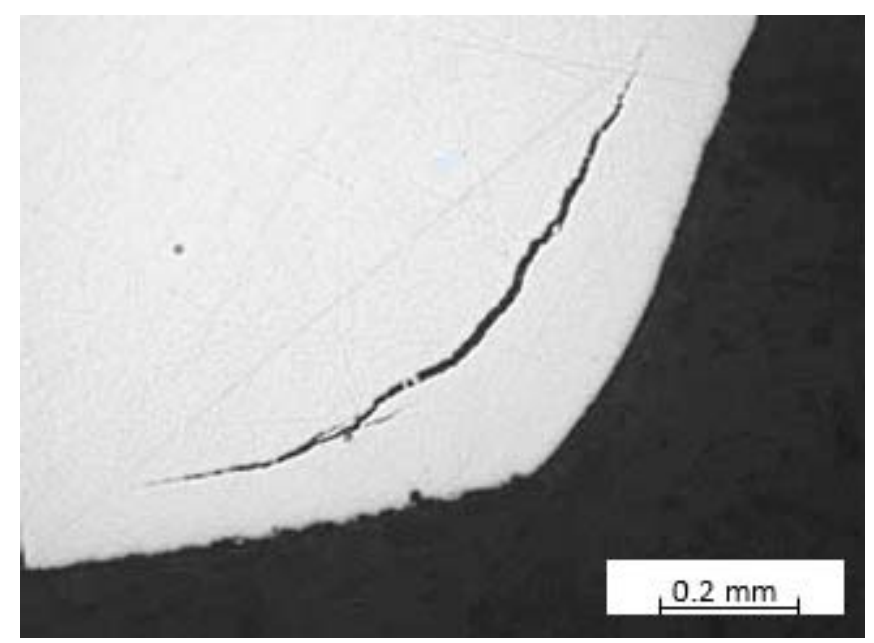

Fig. 13. Rotor. Visible cracks developing parallel to the tooth surface. LM

Another observed form of destruction of satellites is presented in Fig. 14. The maximum shear stress occurred at some distance, usually 0.18-0.3 $\mathrm{mm}$ [10], below the surface, and just ahead of the contact point. Cracks initiated at the point of maximum stress, and propagated essentially parallel to the surface. Continued rolling caused the cracks to deviate up towards 
the contact surface, resulting in the removal of metal from the surface. The pits formed in this manner initially had sides perpendicular to the contact surface. Continued operation of the pitted surface, however, caused a breakdown in the pit shape.

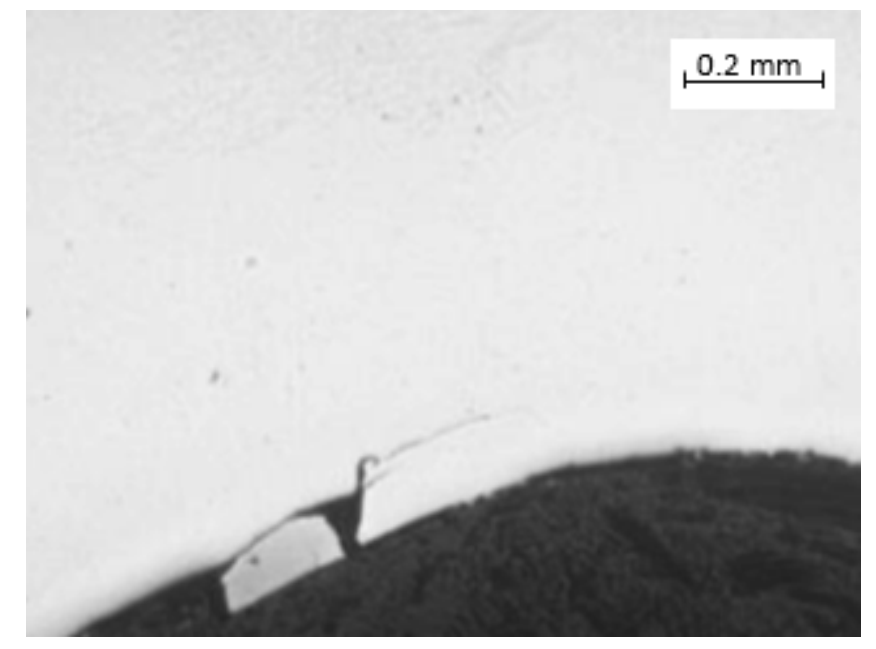

Fig. 14. Visible orientation of subsurface crack at the dedendum of satellite. LM

\section{CONCLUSIONS}

From the experimental observations, the following conclusions may be made:

1. The durability of the hydraulic satellite motor working mechanism at a load, corresponding to a pressure of $15 \mathrm{MPa}$ supplied with refined rapeseed oil is very low. Overload caused fast damage of the working mechanism.

2. The satellites were the weakest part of the pump. In the teeth cooperation area occurred slippage accelerating the process of tooth wear. The satellites were the smallest gear and underwent more revolutions, and therefore each tooth experienced a larger number of stress cycles. Satellites ought to be harder than the other gears in the gear set.

3. Bending fatigue and surface contact fatigue of the satellites were the main cause of the hydraulic satellite motor working mechanism failures.

\section{ACKNOWLEDGEMENTS}

This work has been performed in the scope of the project LIDER "New elaborate of hydraulic satellite machines for drives with organic liquids and non-flammable liquids", which has been financed by The National Centre for Research and Development under the contract LIDER/35/102/L-2/10/NCBiR/2011.

\section{REFERENCES}

1. Śliwiński P.,, Satellite operating mechanism of hydraulic positive displacement machines, Poland, 2012.

2. Śliwiński P., R\&D of satellite pumps and motors with small geometrical displacement supplied with oil and non-flammable liquids, in: C.J. Tadeusz (Ed.), Developments in mechanical engineering Gdańsk University of Technology, Gdańsk, 2012. 
3. Śliwiński P.,, Results of developmental research of hydraulic satellite motors series of types SM (in Polish), in: K.M.M. Centre (Ed.), Research, design, production and operation of hydraulic systems (in Polish), „Cylinder” Library, Gliwice, 2010.

4. Balawender A., Śliwinski P., Developmental research of hydraulic satellite motors and satellite pump with small geometrical displacement supplied with water, emulsion and oil (in Polish), Gdansk University of Technology, 2010.

5. Balawender A., Physical and mathematical model of losses in hydraulic motors. Gdansk University of Technology, Gdansk, 2005.

6. Balawender A., Elgert K., Research on development of satellite hydraulic motors of III generation (in Polish), KBN no. 8T07C04720, Gdansk University of Technology, 2003.

7. Łubiński J., Śliwiński P., Multi parameter sliding test result evaluation for the selection of material pair for wear resistant components of a hydraulic motor dedicated for use with environmentally friendly working fluids, Wear Processes Szczecin, 2012.

8. Fernandes P.J.L., McDuling C., Surface contact fatigue failures in gears. Engineering Failure Analysis, 4 (1997), 99-107.

9. Fernandes P.J.L., Tooth bending fatigue failures in gears. Engineering Failure Analysis, 3 (1996), 219-25.

10. Alban L.E., Systematic analysis of gear failures. American Society for Metals International, Metals Park, Ohio, 1985.

11. Pilkey D.F., Pilkey W.D., Stress concentration factors. Wiley \& Sons, Incorporated, John, 2008.

12. Boniardi M., D'Errico F., C. Tagliabue. Influence of carburizing and nitriding on failure of gears - A case study. Engineering Failure Analysis, 13 (2006), 312-39.

13. Fu G., An Extension of Hertz's Theory in Contact Mechanics. Journal of Applied Mechanics, 74 (2006), 373-4.

14. Sekercioglu T., Fracture analysis of gear pump used for polymer production. Engineering Failure Analysis, 13 (2006), 835-42.

15. Genel K., Demirkol M., Effect of case depth on fatigue performance of AISI 8620 carburized steel. International Journal of Fatigue, 21 (1999), 207-12.

16. Product catalogue, Udeholm, www.udeholm.pl

17. Olsson H., Ukonsaari J., Wear testing and specification of hydraulic fluid in industrial applications. Tribology International, 36 (2003), 835-41.

18. ASM Metals Handbook, Failure of Gears. American Society for Metals, Metals Park Ohio, 1975.

19. Wulpi D.J., Understanding how components fail. American Society for Metals International, Materials Park, Ohio, 1985.

20. Errichello R., Morphology of micropitting. Gear Technology, (2012), 74-81.

21. Śliwiński P., Satellite pump and motor. Machines, Technologies, Materials, 9 (2014), 8-11.

22. Patrosz P., Śliwiński P., Compact satellite hydraulic unit. Machines, Technologies, Materials, 9 (2014), 17-20. 